\title{
Development of sandwich ELISA systems for the diagnosis of hepatitis $B$ virus surface antigen and its antibody in human sera
}

\begin{abstract}
Hepatitis B is an infection of the liver caused by the Hepatitis B virus (HBV). HBV is one of the major causes of acute and chronic hepatitis, cirrhosis and hepatocellular carcinoma, and it is a serious global public health problem. It is estimated that 350 million individuals worldwide are infected with the virus, which causes 620,000 deaths each year. People most at risk include antibody who has unprotected sexual intercourse, drug users who share needles and syringes, health care workers in contact with potentially contaminated blood or body fluids, anyone in intimate contact with the infected person. Therefore, the development of economic and accurate detection systems and potential alternative antiviral approaches for HBV detection could be important for fighting viral hepatitis. Hepatitis B diagnosis has been based on the detection of serologic markers. Testing for these markers helps to determine the presence of past or ongoing HBV infection, the acute, chronic or subclinical carrier state of the disease, response to therapy, and/or the immune status of the patient. Hepatitis B virus surface antigen (HBsAg) is the first serological marker to appear in the circulation, well before clinical symptoms, and is the viral component usually found in the highest concentration in the serum of HBV-infected patients. The presence of anti-HBs in serum indicates previous exposure to HBV and long-lasting acquired immunity. Low serum titres of anti-HBs, however, it can signal a lack of immunity to future HBV infection. In this study, diagnostic systems based on the use of monoclonal antibody $(\mathrm{MAb})$ and polyclonal antibodies (PAb) were developed and conjugated enzyme and biotin for early and sensitive diagnosis of Hepatitis B which is still one of the important infectious diseases in Turkey. Sandwich ELISA kit systems were generated by using both 2G3 MAb (as capturing agent) and 2G3-HRP or 2G3-biotin conjugates (as detecting agents). Homemade sandwich ELISA tests were compared with the other conventional sandwich ELISA tests by using hepatitis B positive and negative infection serum. They were shown that our system gave reliable results. When the homemade HBsAg ELISA system were compared with the other commercial kit by using 280 patients' sera, it was shown that our system corresponded with the results of negative and positive samples at ratio of $96 \%$. When the homemade anti- HBsAg ELISA system was compared with the commercial kit by using 173 patients' sera, it was shown that our system corresponded with the results of negative and positive samples at ratio of $91 \%$. In subsequent studies by the final tests of homemade ELISA kit, it was observed that Biotin-labeled kits responded very close results with the $97 \%$ conformity level when compared with commercial kits.
\end{abstract}

Volume 6 Issue 2 - 2018

Fatima Yucel, Esin Akcael

Tubitak Marmara Research Center, Genetic Engineering and Biotechnology Institute, Turkey

Correspondence: Fatima Yucel, Tubitak MRC, Genetic Engineering and Biotechnology Institute P.O. Box 21, 4I470 Gebze, Kocaeli, Tel +90.262.6773336, Fax +90.262.64I2309, Turkey, Email: fatma.yucel@tubitak.gov.tr

Received: December 27, 2017 | Published: March 14, 2018

\section{Introduction}

Hepatitis B is an inflammatory disease of the liver caused by the Hepatitis B virus (HBV), which is a member of the Hepadnaviridae (Hepa=liver; DNA=deoxyribonucleic acid) family. HBV infection is a quite important global public health problem. According to the World Health Organization (WHO) statistics, 2 billion people have been infected with HBV and an estimated 780000 people die each year from hepatitis worldwide. Around 650000 people currently have chronic infections, and 130000 new acute clinical cases occur annually. ${ }^{1-4}$ Chronic HBV infection is the primary cause of cirrhosis and hepatocellular carcinoma (HCC). HCC is the most common primary liver cancer $(80 \%-90 \%)$ and represents more than $5.7 \%$ of all cancers. Therefore, the development of economic and accurate detection systems and potential alternative antiviral approaches for HBV detection could be important for fighting viral hepatitis.
Hepatitis B vaccination is widely used for the successful prevention of HBV infection but it is still a serious health problem. Because the infection is spread primarily through percutaneous contact with infected blood, e.g., sharing of needles by drug addicts or transfusion of blood products that have not been screened for HBV. The hepatitis B virus is also found in virtually every type of human body fluid and has been known to be spread through oral and genital contact. HBV can be transmitted prenatally from mother to child. ${ }^{5-8}$ Hepatitis B surface antigen is an critical viral envelope protein, which may be detected 30 to 60 days after infection and is a key serological marker for detection and diagnosis of HBV. Hepatitis B diagnosis has been based on detection of serologic markers. Testing for these markers helps to determine the presence of past or ongoing HBV infection, the acute or chronic HBV infection stage of the disease, response to therapy, and/or the immune status of the patient. The most 
commonly used diagnostic and blood screening markers sought is Hepatitis B surface antigen (HBsAg). HBsAg is the earliest indicator of an active hepatitis B infection. The significance of HBsAg in serum is determined by evaluating it in the relationship to the presence or absence of the other HBV markers and the clinical presentation and history of the patient. However, HBsAg test, however, is of particular relevance in the screening of blood donations, for reducing the incidence of post-transfusion HBV hepatitis.

Hepatitis B surface antibody usually appears about 4 weeks after HBsAg disappears and this means that the infection is at the end of its active stage and the patient or carrier cannot pass the virus to others. This antibody also protects people from getting HBV again in the future. The test is performed to determine the need for vaccination. The antibody will be present after receiving the HBV vaccine series, showing that people have protection from the virus. The most widely used HBsAg and anti-HBsAg screening tests are ELISAs they are the most appropriate for screening large numbers of specimens on a Daily. ELISA is a sensitive and specific assay for the detection and quantitation of antigens or antibodies. ${ }^{9}$

In this study, we developed a diagnostic kit based on sandwich Enzyme-Linked Immunosorbent Assay (ELISA) system for the determination of HBsAg and anti-HBsAg in human serum. For this system, we used anti-HBsAg monoclonal antibody (2G3) and polyclonal antibody which had already been developed in our laboratory. The monoclonal antibody (MAb) was conjugated with horseradish peroxidase (HRP) and biotin. HRP conjugated MAb was treated to accelerated stability test and then used in the sandwich ELISA system. Homemade sandwich ELISA system was compared with the other conventional kits by using patients' sera. In our country, most of the diagnostic kits used for the diagnosis of various human diseases, as well as hepatitis, were imported. The use of such diagnostic kits causes economical dependency on foreign countries and also causes important economical losses because of its high cost

\section{Material and methods}

\section{Antibody production and purification}

Monoclonal antibody (2G3) which was used in diagnostic kit system was recently developed in a previous project in our lab. ${ }^{10-12}$ Anti-HBsAg monoclonal antibody, 2G3, had higher affinity for the HBsAg (ad/ay) - did not show any cross reaction with the negative human serum. Monoclonal antibody was found to be of IgG2a subtype by using a hybridoma subisotyping kit (Behring Diagnostics-, La Jolla) system. For polyclonal antibody production, the rabbit was immunized with Hepatitis B surface antigens (HbsAg). Hepatitis B surface antigen $(\mathrm{HbsAg})$ ay and $\mathrm{HbsAg}$ ad types were commercially obtained from Chemicon (cat.no. AG-850, AG-852). The rabbit was immunized subcutaneously and intramuscularly with $8 \mu \mathrm{g} \mathrm{HbsAg}$ at three week intervals. Immunization was performed in the presence of Freund's Complete and Incomplete Adjuvant (FCA and IFA). The rabbit serum was collected and purified by immunoaffinity chromatography using solidphase bound protein A (Staphylococcus aureus) as the IgG-immunotrap (Pharmacia- Uppsala, Sweden).

Both monoclonal antibody and polyclonal antibody were purified from the hybridoma culture supernatant and the rabbit serum by (NH4)2 $\mathrm{SO} 4$ precipitations between 30 and 50\% saturation respectively. The precipitate dissolved and dialyzed against PBS and the antibodies were purified by immunoaffinity chromatography using solid phase bound protein A (Staphylococcus aureus) as the IgG- immunotrap (GE)

\section{Preparation of conjugate antibody (Anti-HBsAg) and antigen (HBsAg)}

Monoclonal antibody (2G3) and Hepatitis B surface antigen (HBsAg) ay and HBsAg ad types were used for conjugation separately. Same methods have been used for antibody and antigen conjugation.

Horseradishe peroxidase- (HRP) labeling of monoclonal antibody: The enzyme-antibody (Anti-HBsAg) and the enzymeantigen ( $\mathrm{HBsAg}$ ) conjugate were prepared as described by Nakane et al. ${ }^{13}$ For both HBsAg detection and anti-HBsAg detection kit systems, $2 \mathrm{mg}$ HRP in $0.5 \mathrm{ml}$ redistilled water was added to $0.1 \mathrm{ml}$ freshly prepared $\mathrm{NaIO}_{4}$ solution $0.2 \mathrm{~mol} / \mathrm{L}$. This mixture was stirred for $20 \mathrm{~min}$ at room temperature. POD-aldehyde solution was dialyzed against sodium acetate buffer overnight at $4^{\circ} \mathrm{C}$. Then purified monoclonal antibody or HBsAg $(4 \mathrm{mg})$ were added to this mixture and stirred for $2 \mathrm{~h}$ at room temperature. $\mathrm{NaBH}_{4}-$ solution $(4 \mathrm{mg} / \mathrm{ml})$ was added and allowed to stand for $2 \mathrm{~h}$ at $4^{\circ} \mathrm{C}$ with occasional shaking. The reaction mixture was dialyzed against PBS buffer and stored at $4^{\circ} \mathrm{C}$. For the stabilization of conjugate one granule of thymol was added.

Monoclonal antibody was used for both captured and conjugated antibody but polyclonal antibody only was used capture antibody in the sandwich ELISA systems for HBsAg detection. HBsAg also was used for both captured and conjugated antigen for anti- HBsAg detection system. The MAb-HRP conjugated was exposed to accelerated stability experiment to detect its shelf life and activity. ${ }^{14,15}$

Biotin labeling of antibodies: Biotin labeling of $2 \mathrm{G} 3 \mathrm{MAb}$ was achieved with amin reactive biotinylation agent N-hydroxysuccinimidobiotin (NHS-Biotin; H-1759, Sigma, USA) in order to use in Biotin/avidin sandwich ELISA kit system. Before labeling, purified $2 \mathrm{G} 3 \mathrm{MAb}$ was dialyzed against $0.1 \mathrm{M}$ sodium carbonate buffer $\left(\mathrm{NaHCO}_{3}, \mathrm{pH}: 99\right)$ overnight. $1 \mathrm{mg} / \mathrm{ml}$ solution of NHS-Biotin was prepared in anhydrous DMSO. 125U1 of NHS-biotin was added to $1 \mathrm{mg}$ of antibody with gentle stirring and incubated at room temperature for 4 hours. After reaction solution was dialyzed against PBS, biotinylated antibody was stored at $-20^{\circ} \mathrm{C} . .^{16}$

\section{The principle of sandwich ELISA test for detecting HBsAg}

An innovative quick ELISA test system was applied for HBsAg detection. The double antibody-sandwich ELISA was used for detecting HBsAg in human serum in this test system (Figure 1). According to the principle of the assay, both anti-HBsAg monoclonal antibody (MAM 2G3) and anti-HBsAg polyclonal antibody was bound to the different ELISA microplates as a capture antibody. Anti-HBsAg linked horseradishe peroxidase (MAM 2G3-HRP) or biotin (MAM 2G3-Biotin) conjugate were used as detecting antibody respectively. Unlike the conventional ELISA systems, the same monoclonal antibody (MAM 2G3) against HBsAg was used as both capturing antibody and detecting antibody. MAb-HRP and MAb-Biotin conjugate were diluted 1:1000 in PBS, and human serum were added to the wells simultaneously and incubated for 1 $\mathrm{h}$ at $37^{\circ} \mathrm{C}$. After repeating the washing step for 5 times with washing buffer, the enzymatic activity was detected by substrate buffer $\left(3,3^{\prime}, 5,5^{\prime}\right.$-tetramethyl benzidine (TMB) and hydrogen peroxide for HRP conjugate-antibody. At the same time, streptavidin-HRP was added for antibody-biotin conjugate and then the enzymatic activity was detected the same substrate buffer. 
The commercial coating buffer (Antibody plate coating buffer), blocking buffers (Commercial 1 (Immunochemical), Commercial 2-(Thermo block) and milk powder), and conjugate diluents (Commercial 1 (Pierce), Commercial 1-containing rabbit serum, PBS containing rabbit serum, Commercial 2 (immunochemical Poly-poly) were used in our kit systems.

i. Well coated with anti-HBs antibody (2G3, MAb/ PAb).

ii. HBsAg from sample or control.

iii. Enzyme tracer: anti-HBsAg antibody (2G3) conjugated to HRP

iv. Enzyme activity is measured by adding TMB substrate buffer

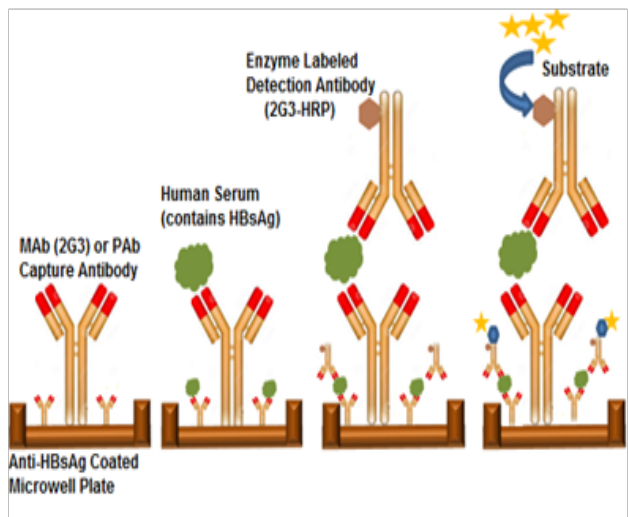

Figure I Diagram of "antigen sandwich" ELISA for the detection of $\mathrm{HBsAg}$ (HRP labeled).

The principle of sandwich ELISA test for detecting Anti-HBs antibody

The double antigen- non-competitive sandwich ELISA assay was used for detecting qualitative/quantitative Anti-HBs antibody in human serum (Figure 2). According to the principle of the assay, ELISA microplates were coated with 250ng commercial HBsAg. After blocking, human serum was added to the microwells together with Horseradish Peroxidase (HRP) conjugated commercial HBsAg. After incubation, the complex of antigen-antibody-antigen (HRPconjugated HBsAg, anti-HBsAg antibody and HBsAg on the wells) would be formed. Thus, the amount of HRP-HBsAg bound to the well was proportional to the concentration of anti-HBsAg antibody in the samples. The unbound enzyme conjugates would be washed away and then the substrate buffer was added to the wells. A blue color was developed in proportion to the amount of anti-HBsAg antibody in the human samples. The enzyme-substrate reaction was stopped by the addition of stop solution. The absorbance of controls and samples were determined by using EIA reader with wavelength set at $450 \mathrm{~nm}$.

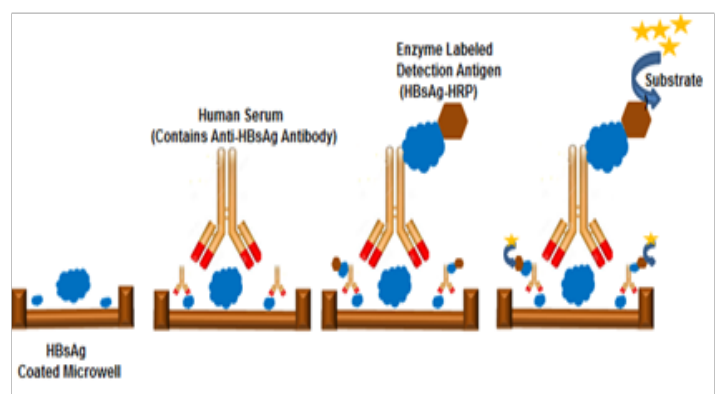

Figure 2 Diagram of "antibody sandwich" ELISA for the detection of anti$\mathrm{HBsAg}$. i. Well coated with commercial human HBs Ag (ad/ay)

ii. Anti- HBsAg from human serum or control and Enzyme tracer: anti-HBs antibodies (2G3, mouse Mab) conjugated to HRP were added simultaneously

iii. Enzyme activity is measured by adding TMB substrate buffer

\section{Results}

\section{Use of the diagnostic kit developed for the detection HBsAg in human sera}

Anti HBsAg- MAb (MAM-2G3) and Anti HBsAg Rabbit PAb were used as a capture antibody in this study (Figure 1). Indirect ELISA method was applied to detect the optimal concentrations of both anti $\mathrm{HBsAg-MAb}$ (Figure 3A) and anti HBsAg- PAb (Figure 3B) for using in homemade ELISA kit system. In the result of indirect ELISA study, optimal concentrations of anti HBsAg- MAb and anti HBsAg$\mathrm{PAb}$ were determined as 200ng/well and 500ng/well respectively for capture antibody. In this study, two different conjugates were developed by labeling MAM 2G3 (MAb) with horseradish peroxidase (HRP) and biotin. MAb -HRP and MAb-Biotin homemade conjugate was used for second antibody in sandwich ELISA. Activities of the conjugates (2G3-HRP and 2G3-biotin) were tested by direct ELISA on HBsAg coated (between 5ng-100ng) microwells.

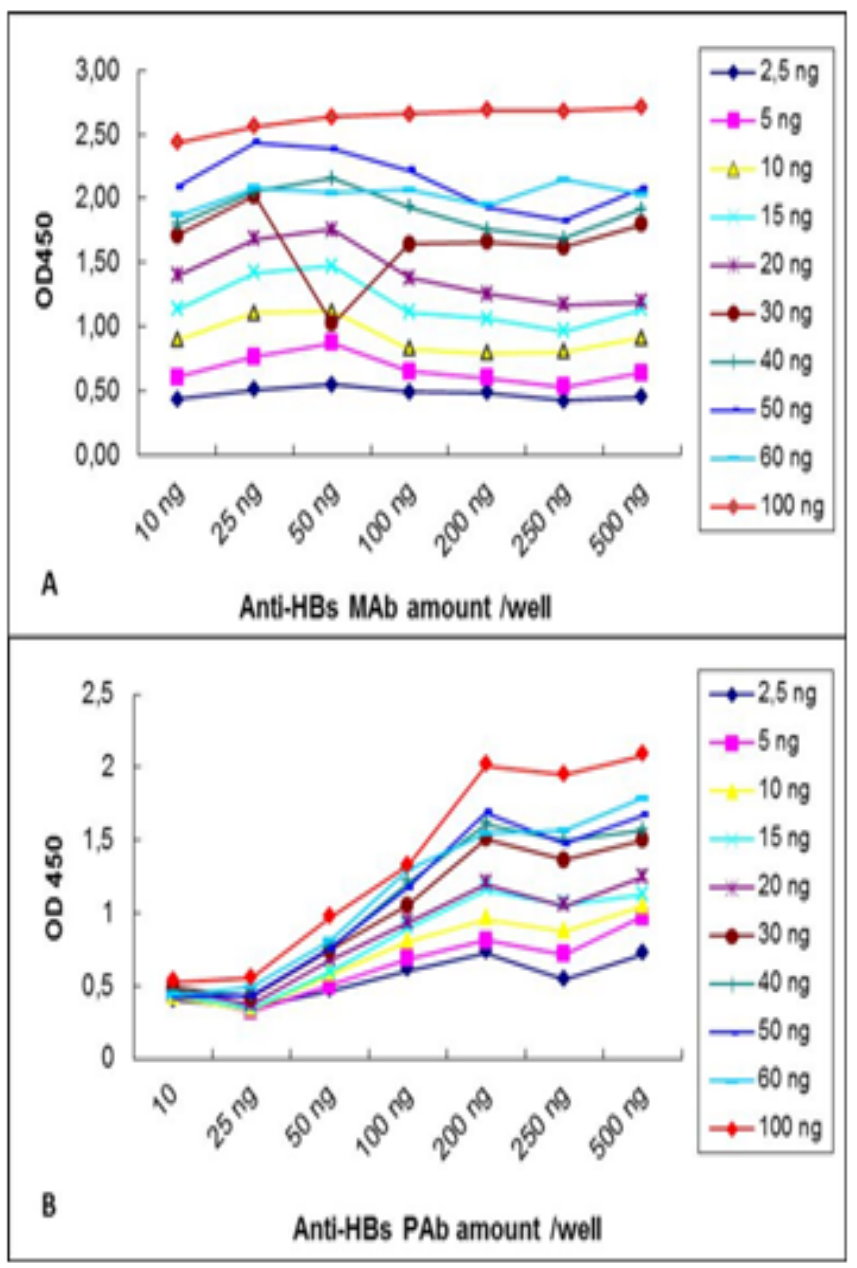

Figure 3 The graph of OD 450 values measured by using $A$ ) different $M A b$ amounts (from IOng/well to $500 \mathrm{ng} /$ well) B) different PAb amounts (from 10 $\mathrm{ng} /$ well to $500 \mathrm{ng} /$ well) in indirect ELISA system. 
In order to detect the optimal concentration of MAM $2 \mathrm{G} 3$-HRP Conjugate and MAM 2G3-Biotin Conjugate, the interaction of MAbHRP conjugate with human serum (as negative control), direct ELISA was realized. Biotin and HRP conjugates responded high absorbance values until 1:16000 and 1:500 dilutions, respectively

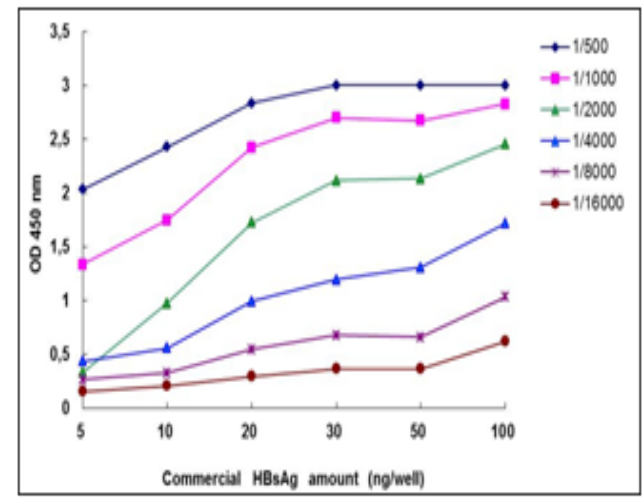

Figure 4 Determination of the optimal concentration of (Anti-HBs -MAM 2G3-HRP) conjugate against HBs antigen by ELISA.

For using in our ELISA kit system, 1/1000 dilution of MAM 2G3HRP Conjugate and MAM 2G3-Biotin Conjugate were found to be the most suitable due to its effectively (Figure 4) (Figure 5). In addition, MAM 2G3-HRP Conjugate and MAM 2G3-Biotin Conjugate didn't give any cross reaction with negative human serum (data not shown).

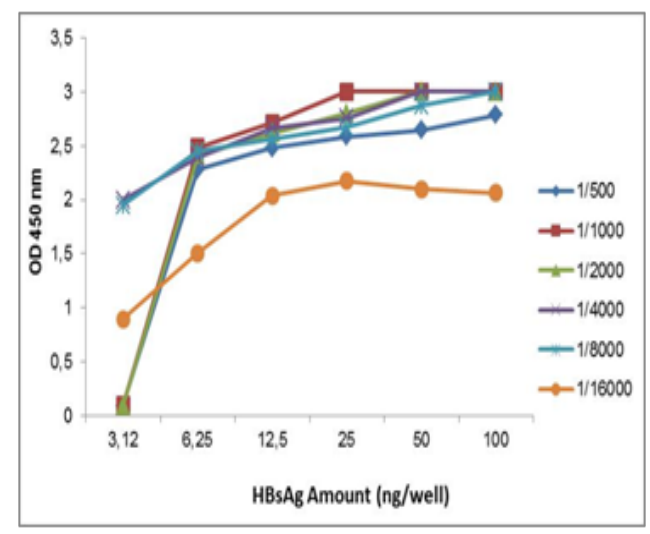

Figure 5 Determination of the optimal concentration of Anti-HBs 2G3Biotin conjugates against HBs antigen by ELISA.

$200 \mathrm{ng} /$ well of anti-HBs 2G3 MAb was coated on ELISA plates. $\mathrm{MAb}$ coated plates results were better than PAb coated plates in laboratory studies, so MAb coated plates were used for sandwich ELISA systems all the field trials. As conjugate, homemade 2G3 MAb-HRP and 2G3 MAb-biotin were used in our ELISA kits. For testing of diagnostic ELISA kit, all validation experiments were done by using infected and non-infected human plasma samples by applying the steps in Figure 1 \& Figure 2. In addition, same samples were tested in commercial kit (Dade Behring, Germany) including biotin conjugate. When HBsAg was present in human serum, it bound to both the captured and the conjugated antibody and the high OD450 values were measured. When HBsAg antigen was not in the human serum, it didn't bind to any antibodies and the low OD450 values were measured on a Bio-Tech EIA reader. Infected and non-infected human plasma samples were obtained from The Istanbul Faculty of
Medicine, ELISA Lab. In the studies of ELISA kit, HRP-conjugate and biotin conjugates were diluted in commercial conjugate diluent (Pierce). During the optimization studies, conjugate diluent was modified by adding the different percentages of the several animal sera (goat, mouse, fetal bovine) in PBS. Figure 6 shows that comparison of the field trials between homemade and commercial HBsAg ELISA kit with human sera.

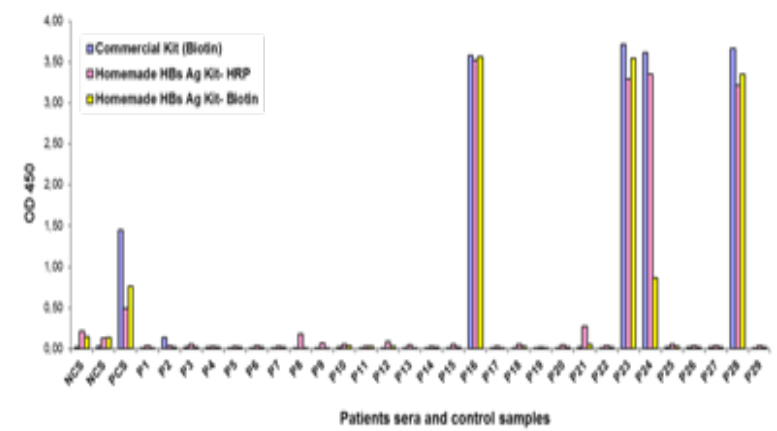

Figure 6 OD450 absorbance values obtained in sandwich ELISA kit for $\mathrm{HBs} \mathrm{Ag}$ positive and negative human serum samples (30 patients) and positive and negative control serum (PCS and NCS) (ELISA plates coated with 200ng/ well anti-HBs Ag 2 G3 MAb).

The results showed that Biotin-labeled kits responded very close results with the commercial kits. In subsequent studies, when the homemade ELISA system were compared with the other commercial kit by using 280 patients' sera, it was shown that our system corresponded with the results of negative and positive samples at ratio of $96 \%$.

\section{Use of the diagnostic kit developed for the detection anti-HBsAg in human sera}

HBsAg -HRP conjugate was used for second detecting antigen in anti-HBsAg detection kit system. Availability of the HBsAg-HRP conjugate was tested. In order to detect the optimal concentration of homemade HBsAg-HRP conjugate and the interaction of antiHBsAg monoclonal $(20,50,100,200 \mathrm{ng} /$ well $)$ and polyclonal antibody $(100,250,500,1000 \mathrm{ng} /$ well) were realized by using direct ELISA. 1/1000 dilution of HBsAg-HRP conjugate was found to be as the most suitable due to its effectivity when the tested with monoclonal (Figure 7) and polyclonal capture antibody (Figure 8). All validation experiments of homemade the double antigen- non-competitive sandwich ELISA test system for detecting anti-HBsAg were done by using positive and negative human serum samples. For anti-HBsAg detection, commercial HBsAg-HRP Conjugate and homemade HBsAg-HRP Conjugates were compared with the several human serum samples contain anti-HBsAg antibody (PS1, PS2, PS3, PS4) and non- anti HBsAg antibody (NS1,NS2,NS3) and positive antiHBsAg antibodies (K1+(10ng), K2(50ng), K3+(100ng) by using sandwich ELISA (Figure 9).

When anti-HBsAg was present in human serum, it bound to both the captured HBsAg and the detected HBsAg-HRP conjugate and the high OD450 values were measured by ELISA reader. When antiHBsAg antibody was not in the human serum, it didn't bind to any antigen and the low OD450 values were measured. The homemade ELISA system was compared with the commercial kit by using 173 patients' sera, it was shown that our system corresponded with the results of negative and positive samples at ratio of $91 \%$. 


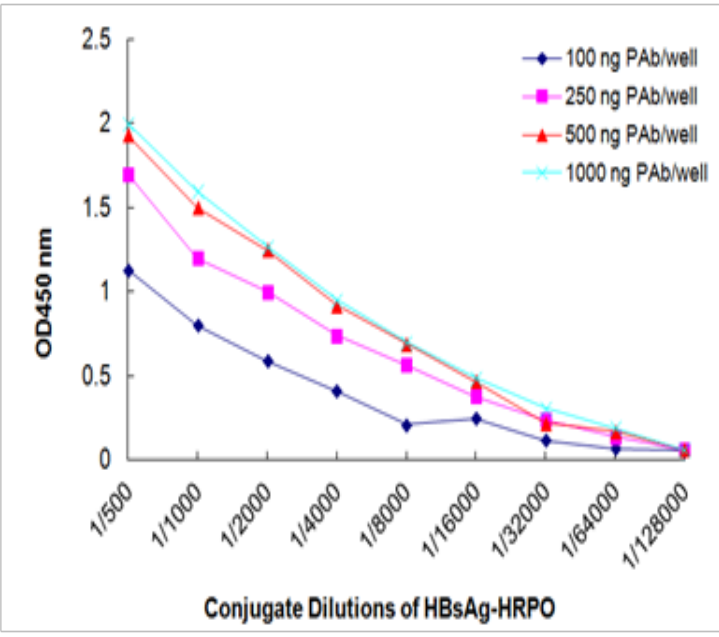

Figure 7 OD 450 absorbance values obtained by direct ELISA for determining of optimal concentration of HBsAg-HRP Conjugate (Plate coated with 20,50,100 and 200ng/well anti-HBs Ag monoclonal antibody; MAM 2G3).

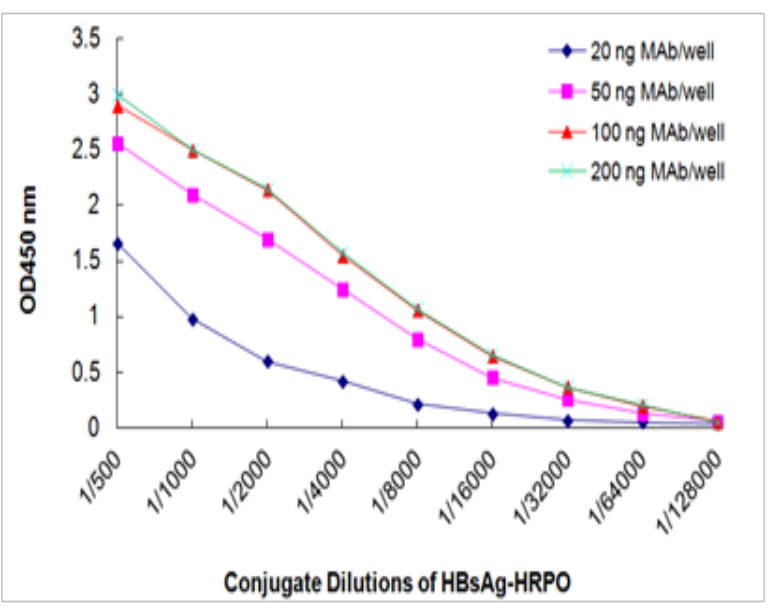

Figure 8 OD 450 absorbance values obtained by direct ELISA for determining of optimal concentration of HBsAg-HRP Conjugate (Plate coated with 100,250,500 and 1000 ng/well anti-HBs Ag polyclonal antibody; rabbit).

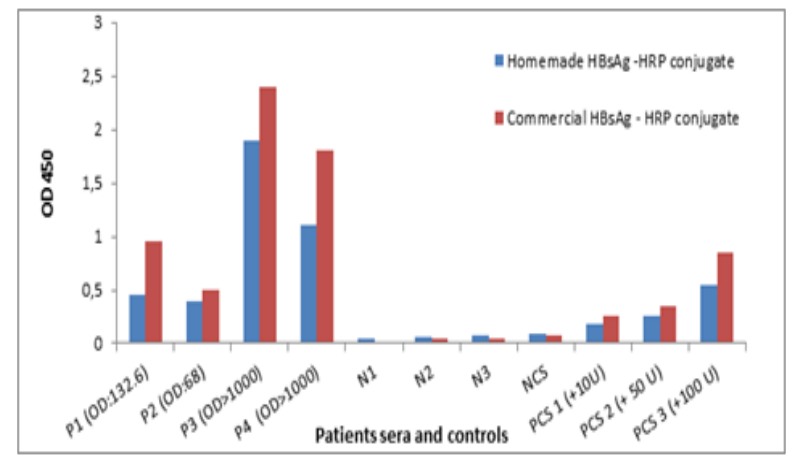

Figure 9 OD450 absorbance values obtained in sandwich ELISA kit for anti- $\mathrm{HBsAg}$ positive (PI, P2,P3,P4)) and negative (NI,N2,N3) human serum samples and positive (PCS) and negative control serum (NCS) . ELISA plates coated with $250 \mathrm{ng} /$ well $\mathrm{HBs} \mathrm{Ag}$.

\section{Discussion}

Sensitive enzyme immunoassays used to detect the presence of HBsAg were first described by several researcher in $1971 .{ }^{17-20}$ In 1976 and 1977, solid phase "sandwich" enzyme immunoassays for the detection of HBsAg were described by Wisdom, Wolters and Wei. ${ }^{21-23}$ The production, characterization and application of monoclonal antibodies for the detection of HBsAg has previously been reported, ${ }^{24-26} \mathrm{HBsAg}$ levels in blood are high as long as the viral particles continue to exist in the liver cells. Hence they are the most important markers used in screening for the presence of Hepatitis B infection in many of the diagnostic test kits in the market. On the other hand, the presence of anti-HBs in serum indicates previous exposure to HBV and long-lasting acquired immunity. Low serum titres of anti-HBs can signal a lack of immunity to future HBV infection. Currently available ELISA diagnostic kits for HBV are both imported and expensive. The main objective of this study was to develop a cost-effective homemade Enzyme-linked Immunosorbent Assay (ELISA) kit for detection of HBsAg and anti-HBsAg in serum using monoclonal/polyclonal antibodies and antibody-conjugates produced in our laboratory.

In this study, sandwich ELISA kits by using monoclonal/polyclonal antibodies and antibody conjugates were developed for diagnosis of Hepatitis B virus. 2G3MAb with high specificity for Hepatitis B virus surface antigen (HBsAg) had already been produced in our previous project. We tested both monoclonal and polyclonal antibody for capturing antibody. MAb coated plates results were better than PAb coated plates in laboratory studies (data not shown), so MAb coated plates were used for sandwich ELISA systems all the field trials. Two different conjugates were developed by labeling 2G3 monoclonal antibody (MAb) with biotin and horseradish peroxidase (HRP) for HBsAg kit. Activities of the conjugates (2G3-HRP and 2G3-biotin) were tested by direct ELISA on HBsAg coated microwells.

In our Sandwich ELISA kit systems, the same monoclonal antibody (Anti HBs 2G3 MAb) against HBsAg was used as both capturing antibody and detecting antibody. In direct ELISA test, biotin and HRP conjugates responded high absorbance values until 1:64000 and 1:16000 dilutions, respectively. The optimum dilutions of 2G3-HRP and 2G3-Biotin had been determined as 1/1000 to use them in ELISA kit applications, In addition to this, conjugate diluent was developed by adding $5 \%$ of several animal sera in PBS. For HBsAg detection, ELISA test systems of HRP and biotin were compared by using hepatitis B positive and negative human sera. We tested 280 human sera which were HBsAg suspected patients and also 173 human sera which were Anti-HBsAg suspected patients. When the homemade HBsAg ELISA system were compared with the other commercial kit by using 280 patients' sera, it was shown that our system corresponded with the results of negative and positive samples at ratio of $96 \%$.

For anti-HBsAg detection, we conjugated commercial HBsAg antigen with the HRPO and determined the optimal dilutions of this conjugate as a $1 / 1000$ to use them in ELISA kit applications. The homemade anti-HBsAg ELISA system was compared with the commercial kit by using 173 patients' sera, it was shown that our system corresponded with the results of negative and positive samples at ratio of $91 \%$. The performance of homemade HBsAg and AntiHBsAg kits was compared with the commercial ELISA kits (eighth generation kit). All reference plasma samples, kindly provided by Dr. Derya Onel (Istanbul University, Capa Medical Faculty, and 
Microbiology Department) contained positive and negative human sera. The sandwich ELISA tests reviewed over the controls of the commercial kit both HBsAg and anti-HBsAg homemade kit.

In subsequent studies by the final tests of homemade ELISA kit, it was observed that Biotin-labeled kits responded very close results with the $97 \%$ conformity level when compared with commercial kits.

\section{Acknowledgements}

The authors are grateful to Aliihsan Manav and Harun Kocaağa for their technical assistance. This work has been supported by TUBITAK Public Research Grant Committee (KAMAG 1007 - 105G056).

\section{Conflict of interest}

The author declares no conflict of interest.

\section{References}

1. http://www.who.int/mediacentre/news/releases/2015/hepatitis-bguideline/en/

2. Chisari FV, Ferrari C. Viral Hepatitis. In: Nathanson N, editors. Viral Pathogenesis. Philadelphia: Lippincott; 1997:745-778.

3. Ganem D, Schneider RJ. Hepadnaviridae: The Viruses and Their Replication. In: Knipe DM, editors. Fields Virology. 4th ed. Philadelphia: Lippincott Williams \& Wilkins; 2001:2923-2969.

4. Zuckerman AJ. Hepatitis Viruses. In: Medical Microbiology. USA: Barron; 1996.

5. Weinbaum CM, Williams I, Mast EE, et al. Recommendations for identification and public health management of persons with chronic hepatitis B virus infection. Hepatology. 2009;49(5 Suppl):S35-44.

6. Pereira A, Sanz C, Tàssies D, et al. Do patient-related blood donors represent a threat to the safety of the blood supply. Haematologica. 2002;87(4):427433.

7. Goldman M, Xi G, Yi QL, et al. Reassessment of deferrals for tattooing and piercing. Transfusion. 2009;49(4):648-654.

8. Hilleman MR. Critical overview and outlook: pathogenesis, prevention, and treatment of hepatitis and hepatocarcinoma caused by hepatitis B virus. Vaccine. 2003;21:4626-4649.

9. John R Crowther. The ELISA guidebook. In: Methods in Molecular Biology. Totowo, New Jersey: Humana Press; 2000;149.

10. Basalp A. Monoclonal antibodies against Hepatitis B Virus surface antigen. Hybridoma and Hybridomics. 2002;21(1):81-82.
11. Yucel F, Manav Aİ, Başalp A. Production and characterization of monoclonal antibodies against Hepatitis B viruses and application of a quick sandwich ELISA. Hybridoma and Hybridomics. 2003;22(3):173177.

12. Yücel F, Çırakoğlu B. Monoclonal antibodies against Hepatitis B surface antigen. Hybridoma. 2000;27(4):319-320.

13. Nakane PK, Kawaoi A. Peroxidase-labelled antibody, a new method of conjugation. J Histochem Cytochem. 1974;22(12):1084-1091.

14. Crowther JR. ELISA: Theory and Practice. Methods in Molecular Biology. 1995;42:1-218.

15. Guire P. Stability Issues for Protein-based in vitro Diagnostic Products. IVD Technology. 1999;5:50-54.

16. Howard CG, Kaser CG. Making and Using Antibodies. A practical handbook: CRC Press; 2007.

17. Engvall E, Jonsson K, Perlmann P. Enzyme-linked immunosorbent Assay 11. Quantitation Assay of protein antigen, immunoglobulin G, by means of enzyme-labeled antigen and antibody-coated tubes. Biochim Biophys Acta. 1971;251:427-434.

18. Engvall E, Perlmann P. Enzyme-linked immunosorbent assay (ELISA) Quantitative assay of immunoglobulin G. Immunochem. 1971;8(9):871874.

19. Engvall E, Perlmann P. Enzyme-linked immunosorbent assay (ELISA). In: Peeters H, editor. Protides of the Biological Fluids. Proceedings of Nineteenth Colloquium Brugge: Pergamon Press; 1971:553-556.

20. VanWeemen BK, Schuurs AHWM. Immunoassay using antigenenzyme conjugates. FEBS Letters. 1971;15(3):232-236.

21. Wisdom GB. Enzyme-Immunoassay. Clin Chem. 1976;22(8):1243-1255.

22. Wolters G, Kuijpers L, Kacaki J, et al. Solid-phase enzyme immunoassay for detection of hepatitis B surface antigen. J Clin Pathol. 1976;29(10):873-879.

23. Wei R, Knight GJ, Zimmerman DH, et al. Solid-Phase Enzyme immunoassay for Hepatitis B Surface Antigen. Clin Chem. 1977;23(5):813-815.

24. David GS, Present W, Martinis J, et al. Monoclonal antibodies in the detection of hepatitis infection. Med Lab Sci. 1981;38:341-348.

25. Shih JW-K, Cote PJ, Dapolito GM, et al. Production of monoclonal antibodies against Hepatitis B surface antigen (HBsAg) by somatic cell hybrids. J Virol Meth. 1980;1(5):257-273.

26. Wands JR, Zurawski VR. High affinity monoclonal antibodies to hepatitis B surface antigen (HBsAg) produced by somatic cell hybrids. Gastroenterology. 1981;80(2):225-232. 